\title{
On the hydrological properties of mountain soils, from measurement to the geotechnical implications
}

\author{
Stefano Barontini ${ }^{1}$, Giovanna Grossi ${ }^{1}$, Marco Peli ${ }^{1}$, Roberto Ranzi ${ }^{1}$ and Baldassare Bacchi ${ }^{1}$ \\ ${ }^{1}$ Università degli Studi di Brescia, DICATAM, Via Branze, 43, I-25123, Brescia, Italy
}

\begin{abstract}
Aiming at contributing with a hydrological perspective to the geotechnical investigation in mountain environments, particularly focusing on landslides triggered by perched water tables, we present some findings of a longlasting experimental and theoretical investigation of mountain - soils hydrology. After recalling a theoretical framework suitable to describe the hydrology of shallow, sloping and heterogeneous soils, we discuss some relevant difficulties concerning the measurement of the hydrological properties of heterogeneous and non mature soils, and we finally focus on the role played by the soil heterogeneity in the perched water tables onset.
\end{abstract}

\section{Introduction}

Mountain soils are often young and non mature as the gravity-driven mass movement is one of the major soil forming factors [1]. They are moreover seat of both freezing/thawing and wetting/drying cycles, and of intense biological activity, so that they are also heterogeneous due to the presence of cracks and biogenetic macropores in the uppermost layers [2]. On the other hand mountain soils play an important role in key hydrological processes, as runoff production, groundwater table recharge and evapotranspiration. Moreover in mountain environments, rainfall and the following redistribution of water content are the most common triggers of landslides worldwide [3] and rainfall itself is of crucial importance for the sediment production.

Focusing on landslides, diverse hydrological systems are expected to trigger diverse landslide typologies. According to [3], debris flow will be probably triggered by (surface) runoff; shallow soil slips, ranging from 1 to 2 $\mathrm{m}$, might be caused by percolating water fronts or perched water tables generated by individual storm events; deeper landslides can be described only considering larger windows of meteorological inputs, vegetation and the role of the vadose zone. Within all these schemes, one has also to think about the role of preferential flow phenomena, which can greatly influence the triggering system. Moving from the understanding of the slope hydrology to the failure mechanisms, thus linking the soil hydrology with its geotechnical implications, is still a major challenge [4].

Aiming at contributing with a hydrological perspective to the geotechnical investigation of landslides triggering mechanisms, we present some results of a longlasting experimental and theoretical investigations of the hydrology of mountain soils. After recalling a theoretical framework suitable to describe the hydrology of shallow, sloping and heterogeneous soils (Section 2), we discuss some relevant difficulties concerning the measurement of the hydrological properties of heterogeneous and non mature soils (Section 3). Finally we focus on the role played by the soil heterogeneity in the perched water tables onset (Section 4).

\section{Theoretical framework}

In this work we will describe the soil water dynamics as a (deterministic) Darcian, isothermal and uncompressible flow in a continuum, undeformable and a priori unsaturated porous medium. These assumptions are very common for surface non-swelling soils and allow to describe many practical field conditions, as the soil can be also heterogeneous and anisotropic, although in a deterministic sense. With these assumptions the mass conservation principle, coupled with the Darcy law, takes one of the forms of the Richards equation:

$$
\nabla \cdot(\mathbf{K} \nabla \Phi)=\frac{\partial \theta}{\partial t}
$$

In equation (1) $\mathbf{K}[\mathrm{L} / \mathrm{T}]$ is the soil - water conductivity tensor; $\Phi[\mathrm{L}]$ is the generalized piezometric potential of the soil water; $\theta\left[\mathrm{L}^{3} / \mathrm{L}^{3}\right]$ is the volumetric soil water content. The piezometric potential $\Phi=h(\theta)+z$ is the summation of two components, that are the gravimetric potential $z$ and the tensiometer-pressure potential $h$, which, in an unsaturated soil, is in turn a function of the water content $\theta$ by means of the soil-water retention function. In a heterogeneous and unsaturated soil, the conductivity tensor $\mathbf{K}$ depends both on the position $\mathbf{x}$ and on the soil-water content $\theta$, and it is therefore related to the tensiometer-pressure potential $h$ by means of the rel- 
ative conductivity function $k(h)$, which will be introduced in the Section 2.1.

The Richards equation (1) can be solved once known the soil-water constitutive laws $\theta(h)$ and $k(h)$, in each point of the domain, and once fixed the initial and boundary conditions. In practical way and with a deterministic approach to the soil-water constitutive laws, the upper soil layers are either regarded to as subdivided into homogeneous and layered subdomains, or they are considered gradually varying with the depth in the transverse direction to the soil slope ( $x *$ in Figure 1).

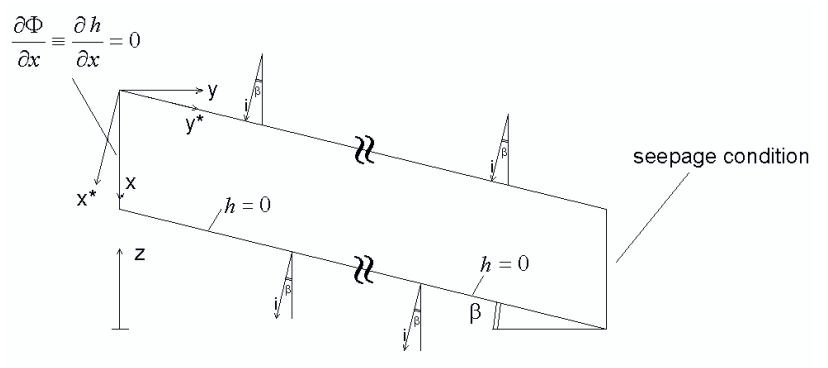

Figure 1. Sketch of a reference draining slope with indicated some typical boundary conditions for numerical simulation.

\subsection{A form for the hydraulic conductivity tensor}

An almost general form of the conductivity tensor $\mathbf{K}$ is given in the following equation (2):

$$
\mathbf{K}(h, \mathbf{x})=K_{s, o} k(h) \mathrm{f}\left(x^{*}\right) \mathbf{k}^{(\mathbf{A})},
$$

in which $K_{s, o}$ is the hydraulic conductivity at soil saturation in the transverse direction $x^{*}$ at the soil surface; $k(h)$ is the relative conductivity function; $\mathrm{f}\left(x^{*}\right)$ accounts for the soil heterogeneity and $\mathbf{k}^{(\mathrm{A})}$ is the anisotropy tensor. The product:

$$
K_{s}(x *)=K_{s, o} \mathrm{f}(x *),
$$

with $\mathrm{f}\left(x^{*}=0\right)=1$, describes the profile of the transverse conductivity at saturation $K_{s}\left(x^{*}\right)$. The tensor $\mathbf{k}^{(\mathrm{A})}$ accounts for how much lateral conductivities are greater than the transverse one, and in two dimensions takes the following form:

$$
\mathbf{k}^{(\mathbf{A})}=\left[\begin{array}{ll}
1 & 0 \\
0 & r
\end{array}\right],
$$

in which $r$ is the anisotropy coefficient. Equation (2) is written under the assumptions that $(a)$ the soil is heterogeneous in the transverse direction $x^{*}$ and it is homogeneous in the lateral direction $y^{*},(b)$ the principal directions of anisotropy are the transverse $\left(x^{*}\right)$ and the lateral ones $\left(y^{*}\right) ;(c)$ the heterogeneity does not affect the shape and the parameters of the relative conductivity function (and of the soil water retention function as well) but only the value of the hydraulic conductivity at saturation; $(d)$ the anisotropy coefficient $r$ is uniform also in the transverse direction. Assumptions $(a)$ and $(b)$ follow from the hypo- thesis that the transverse direction $x *$ is also the direction of the soil genetic development. Assumption (c) follows from the idea that the conductivity at saturation strongly depends on the soil macropores, while the constitutive laws $k(h)$ and $h(\theta)$ are sensitive to the micropores of the soil matrix.

As a consequence of genetic layering the soil hydraulic conductivity at saturation $K_{s}$ decreases with depth in the transverse direction $x^{*}$ across the upper soil horizons, being typically greater in A horizons, rich in macropores, and smaller in B ones [2]. On mountains, where strongly erosive processes act and mass movement is a key soil forming factor, the soil horizonation cannot fully develop and a gradual decrease of $K_{s}$ typically occurs in the upper soil layers, as it will be showed in Section 3.1. Equation (2), with $\mathrm{f}\left(x^{*}\right)$ smooth and monotonically decreasing with $x^{*}$, is therefore effective in order to describe the $K_{s}$-field on mountain slopes.

\subsection{Bottom boundary conditions and one dimensional formulation}

A key issue which characterises the solution of equation (1), and therefore the prediction of the onset of a perched water table, is to define the boundary condition at the bottom of the investigated soil layer $x_{f}^{*}$. As a first approximation, we define here two reference soil profiles:

(a) Soil which lays on a massive rock or on a massive layer of parent material: the most suitable boundary condition is no flux in the transverse direction $x^{*}$, i.e.:

$$
\left(\frac{\partial \Phi}{\partial x *}\right)_{x_{f}^{*}}=0 \text {. }
$$

In this framework, if a perched water table onsets, the maximum value of the tensiometer - pressure potential will be predicted at the interface between the soil and the parent material;

(b) Soil which lays on fractured rock or on a greatly conductive layer of parent material which is not able to act any retention: the underlying layer behaves as a capillary barrier and suitable boundary conditions are a percolation-like condition, i.e.:

$$
\left(\frac{\partial \Phi}{\partial x^{*}}\right)_{x_{f^{*}}}=-\cos \beta
$$

or a saturation one $\left(h\left(x_{f}^{*}\right)=0\right)$. The first condition applies during transient flow, the latter during steady flux. In this case a perched water table can theoretically onset only if the soil is unhomogeneous and if the hydraulic conductivity at soil saturation monotonically decreases with $x^{*}[5]$.

In case $(b)$, as the percolation can take place, if one focuses on distributed processes (viz those related to rainfall or snow-melting infiltration, redistribution and evapotranspiration) and if the depth of the investigated soil layer is almost uniform along the slope (Figure 1), in the Richards equation (1) the condition of uniform flow: 


$$
\frac{\partial}{\partial y^{*}}(\cdot)=0
$$

holds for each variable (with the exception of $z$ ). The equation (1) is therefore rewritten in a simplified one dimensional form:

$$
\frac{\partial}{\partial x^{*}}\left[K_{s, o} k(h) \mathrm{f}\left(x^{*}\right)\left(\frac{\partial h}{\partial x^{*}}-\cos \beta\right)\right]=\frac{\partial \theta}{\partial t} .
$$

Due to the lateral effect of gravity, this simplification does not mean that the soil is seat of a purely transverse (one dimensional) flow, because a laterally-uniform flow $q_{y^{*}}$, given by:

$$
q_{y *}(x *)=r K_{s, o} k(h) \mathrm{f}\left(x^{*}\right) \operatorname{sen} \beta .
$$

takes place along the soil profile $x^{*}$.

\section{Experimental evidences}

\subsection{Conductivity at saturation}

Several methods are available both in the field and in the laboratory, and depending on the expected values, to determine the conductivity at saturation. Conductivities greater than $10^{-4} \mathrm{~m} / \mathrm{s}$ are typically estimated by means of constant head permeameter or constant head infiltromete$\mathrm{r}$; conductivities ranging from $10^{-8} \mathrm{~m} / \mathrm{s}$ to $10^{-4} \mathrm{~m} / \mathrm{s}$ are estimated also by means of falling head permeameter and falling head infiltrometer; conductivities smaller than $10^{-8}$ $\mathrm{m} / \mathrm{s}$ are usually estimated by means of edometric compression. After a long lasting experimental practice, during which a great number of mountain soils was investigated in the Italian Alps (146 soils in the Toce river basin [6], 100 in the Oglio river basin [7], 127 in the Mella river basin [6]), we observed that falling - head methods were suitable for most of the cases.

In [6] and [7] we provided a detailed discussion about different approaches at interpreting the falling head permeameter and the single ring infiltrometer data. Here we will just recall two important aspects:

(1) The soil volume investigated by the single ring infiltrometer $\left(\sim 10 \mathrm{dm}^{3}\right)$ is much greater than that investigated by the falling head permeameter $\left(\sim 1 \mathrm{dm}^{3}\right)$, therefore the first method allows to better explore the soil discontinuities and macropores, and it is more effective for mountain young soils. Moreover the core disturbance is greater for the second method and the first method is therefore recommended when possible;

(2) The choice of reliable boundary conditions for the falling head permeameter is much easier than for the single ring infiltrometer. It is in fact often difficult to make a priori hypotheses about the shape of the flux and the values of the tensiometer-pressure potential at the bottom of the infiltrometer.

Single ring infiltrometer data can be interpreted by means of a number of methods, viz:
(1) Purely one-dimensional methods, based on the direct integration of Darcy's law across the soil core which is bounded by the infiltrometer;

(2) One-dimensional methods with scaling corrections, which account for the lateral water flow due to the non-saturation of the surrounding soil [8];

(3) Two-dimensional methods with axial symmetry [9];

(4) Inverse modelling (typically in two - dimensional axis - symmetric model) of the infiltration process.

Methods (2) and (3) account in some ways also for the surrounding soil, so that they better describe the infiltration process, but they require that the soil around and below the infiltrometer is uniform. In case the soil is not uniform, an inverse modelling approach is more realistic. By means of all these methods, reliable estimates are obtained if the suction below or around the infiltrometer is accounted for in some ways, otherwise conductivities are meaningfully overestimated.

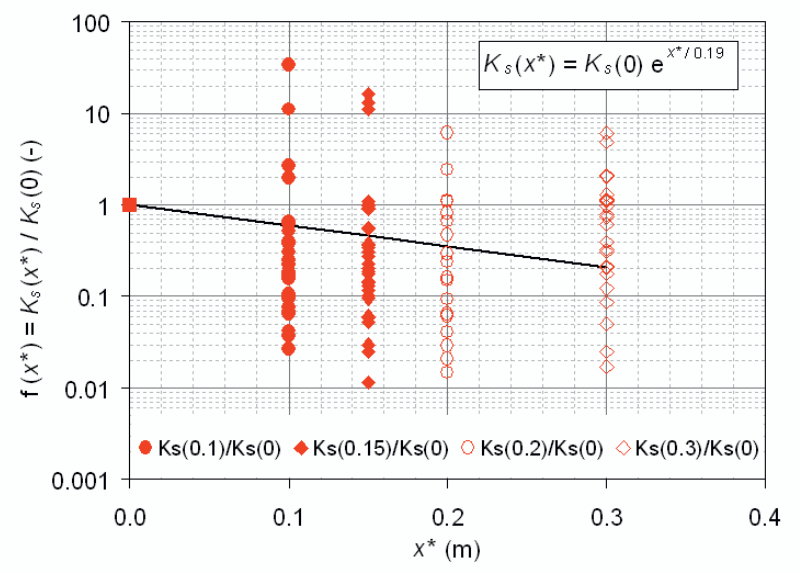

Figure 2. Experimental data about the soil heterogeneity function $\mathrm{f}\left(x^{*}\right)$ defined in eq. (2). Data from two subbasins of the Toce river basin, after [6], modified.

The first class of methods allows to investigate only the soil core inside the infiltrometer, therefore it is the most effective at obtaining conductivity profiles. In order to do so, after performing the first infiltration tests at the soil surface, the first soil layer is removed to perform other infiltration tests at fixed depth. In Figure 2 resulting values of the heterogeneity function $\mathrm{f}\left(x^{*}\right)$ measured in two subbasin of the Toce river basin are represented (after [6], modified). It is observed that in most of the profiles the conductivity values decrease with depth in the uppermost soil layers. According to a common hydrological practice [10] the heterogeneity function $\mathrm{f}\left(x^{*}\right)$ was interpreted by means of an exponential, and we estimated a length of decay $L=0.19 \mathrm{~m}$ and $0.12 \mathrm{~m}$ for the Toce river basin and for the Mella river basin, respectively.

\subsection{Near-saturation conductivity}

During the infiltration and the redistribution process in an unsaturated soil, a major role is played by the relative conductivity function $k(h)$. Typically the shape and the values of $k(h)$ are provided by predictive models [11] 
once known the soil-water retention function $\theta(h)$. Yet $k(h)$ is very sensitive to $h$, especially for nearly saturated soil (e.g. $-30 \mathrm{~cm}<h<0 \mathrm{~cm}$ ), and it is therefore recommended to directly estimate it, at least for few values of $h$, by means of e.g. a tension infiltrometer [9]. This procedure reduces the uncertainties related to the use of the predictive models [12] and allows to estimate the contribution of the macropores to the hydraulic conductivity [13]. If we assume in fact that, in a capillary soil model, the soil-water content $\theta$, in equilibrium at a certain tensiometer-pressure potential $h$, is the pore space volume characterised by local radii smaller than a certain radius $r(h)$, which is function of $h$ by means of the JourinBorelli formula, then the macropores contribution to the conductivity is estimated comparing the conductivity determined by ponded infiltration with that determined at a certain tensiometer-pressure potential $h$. The Authors [13] observed a great decrease in the observed mean infiltration rate in a potential interval ranging from $h=0$ $\mathrm{cm}$ to $h=-3 \mathrm{~cm}$, and they estimated that nearly $73 \%$ of the saturated flux occurred in the pores characterised by this potential interval.

\subsection{Characteristic water contents and soil-water retention functions}

The soil-water content dynamics are bounded by the characteristic water contents, that are the residual water content $\theta_{r}$ and the water content at saturation $\theta_{s}$. These two values represent the minimum soil-water content for which the water phase is continuous, and the maximu$\mathrm{m}$ soil-water content above which the gas phase is discontinuous, respectively. In traditional laboratory practice $\theta_{r}$ is estimated as the asymptote of the soil-water retention function and $\theta_{s}$ as the soil-water content after long imbibition, but they are far from being intrinsic soil properties. Their magnitudes, in fact, seasonally vary due to the soil swelling and to the soil biological activity, and they are moreover affected by the draining and wetting history. These quantities can be therefore regarded to as state variables, and a more reliable estimate is provided by analysing the extreme values reached by field-measured series of soil-water content. It is remarked that during transient analyses, especially of wetting processes and when a perched water table is expected to onset, a crucial role is played by the water content at saturation $\theta_{s}$. As the relative conductivity $k(h)$ is very sensitive to $h$ nearby saturation, then uncertainties on $\theta_{s}$ can sensitively affect the reliability of the description of a perched water table.

The soil-water retention relationships are usually determined in the laboratory by weighting the water content of soil samples at the equilibrium with certain tensiometer - pressure potentials. After that the experimental points are interpolated in order to fit analytical functions in the form $\theta(h)$ or $s(h)$, being $s$ the effective soil saturation, defined by:

$$
s=\frac{\theta-\theta_{r}}{\theta_{s}-\theta_{r}} .
$$

Accounting for the uncertainties at determining the characteristic soil-water contents, and for the disturbance of the laboratory samples, it is suggested to substitute the volumetric soil-water content $\theta$ with the gravimetric one $w$, thus obtaining:

$$
s=\frac{w-w_{r}}{w_{s}-w_{r}},
$$

being $w_{r}$ and $w_{s}$ the residual gravimetric water content and the gravimetric water content at saturation, respectively. Then the soil-water retention curve are interpolated in the form $s(h)$ and can be driven back to the field volumetric soil - water content by means of the field values of $\theta_{r}$ and $\theta_{s}$. This procedure therefore uncouples the laboratory measurements from the field soil structure, and it is closely related to the idea that the retention is mainly due to the soil matrix and less to the soil macropores.

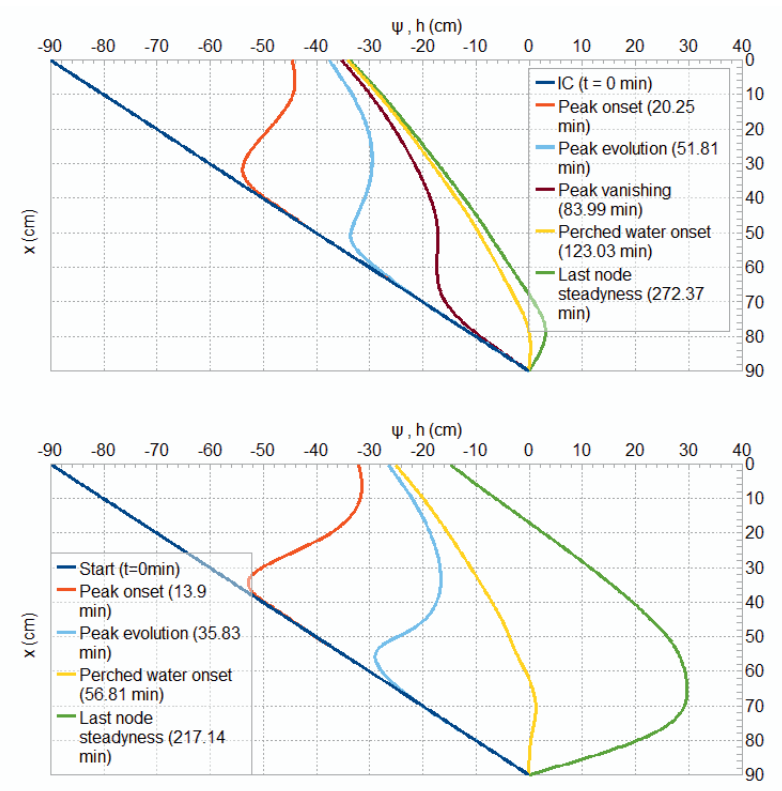

Figure 3. Soil-water content peaks and perched water tables onset in a horizontal, gradually layered and draining soil with decreasing conductivity at saturation with depth [14].

\section{Geotechnical implications}

If the hydraulic conductivity at saturation monotonically decreases with depth, subsurface peaks of water content can onset during long lasting infiltration at low infiltration rates. This pattern was proved for exponentially decreasing conductivity in a horizontal soil [5], and cannot be excluded in any case $K_{s}$ monotonically decreases with depth. Afterwards this pattern was observed by means of a laboratory experiment during which artificial rainfall was poured over a multi-layered soil column characterised by decreasing $K_{s}$ with depth [15]. During the same experiment it was observed that, if infiltration lasts after the water content peak formation, the soil saturation can be reached somewhere below the soil surface. Then a perched water table onsets and develops both upwards and downwards. 
In a soil layer of finite thickness and inferiorly bounded by a capillary barrier, the perched water table may onset or it may not, depending on the infiltration rate and on the values of the conductivity at the bottom of the soil [14]. In Figure 3 two patterns of perched water onset are represented after numerical simulation of a soil with exponentially decreasing $K_{s}$ with depth: in one case (Figure 3 , above) a peak of tensiometer-pressure potential (and of water content as well) onsets and moves downward, then it vanishes and a perched water table onsets starting from the soil bottom; in the other case (Figue 3, below) the peak of tensiometer-pressure potential onsets and emphasizes until it reaches the soil saturation and originates a perched water table.

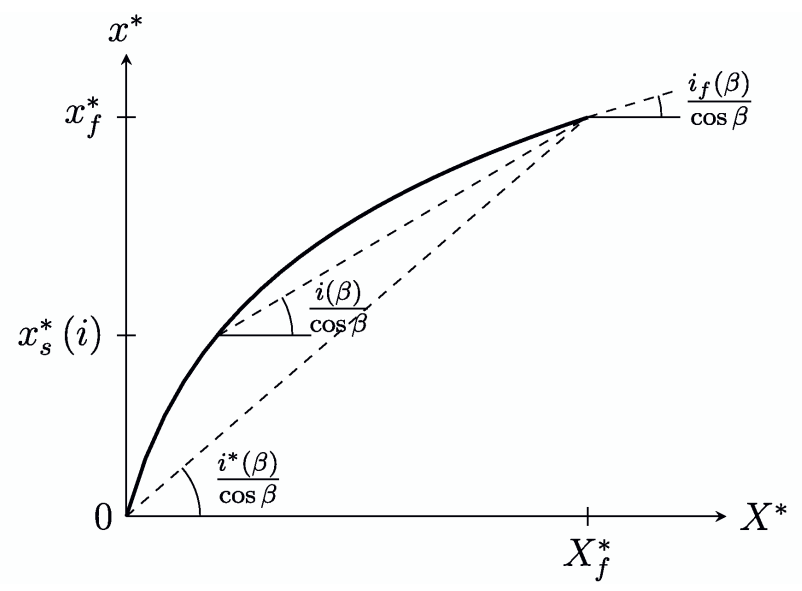

Figure 4. Infiltration thresholds and thickness of the perched water table as a function of $K_{s}\left(x^{*}\right)$ by means of the Zaslavsky transformation $X^{*}\left(x^{*}\right)$ (15) [16].

Infiltration thresholds and properties of the perched water tables (i.e. thickness of the perched water table, position and magnitude of the maximum tensiometerpressure potential) were derived for horizontal soils [17] and then generalised for sloping soils with slope $\beta$ [18]. Here we will recall that, in case of a sloping soil:

(a) The infiltration threshold $i_{f}(\beta)$ at which a perched water table onsets is related to the transverse conductivity $K_{s}\left(x_{f}^{*}\right)$ at the soil bottom $x_{f}^{*}$, as given by:

$$
i_{f}=K_{s}\left(x_{f}^{*}\right) \cos \beta \text {; }
$$

(b) The infiltration threshold $i^{*}(\beta)$ at which the soil reaches waterlogging is related to the equivalent transverse conductivity $K_{s x^{*}, e q}$ between the soil surface $\left(x^{*}=0\right)$ and the soil bottom $\left(x_{f}^{*}\right)$ by means of :

$$
i^{*}=K_{s, \mathrm{eq}} \cos \beta \text {; }
$$

(c) The depth of the maximum tensiometer-pressure potential $h_{\max }$ within a perched water table given by an infiltration rate $i$ is at $x^{*}{ }_{\max }$ where:

$$
K_{s}\left(x{ }_{\max }\right)=\frac{i}{\cos \beta} .
$$

From equations (12), (13) and (14) emerges that the characterizing infiltration rates reduce with the decline from vertical axis $\cos \beta$ because, if the slope increases also the gravitational-potential gradient is less effective at contributing to the transverse flow.

In Figure 4 the previously introduced results are effectively synthesised by means of the classical Zaslavsky transformation of variables [16]. The Zaslavsky transformation [19], defined as:

$$
\mathrm{d} X^{*}=\frac{\mathrm{d} x^{*}}{K_{s}\left(x^{*}\right)},
$$

allows to symbolically map an unhomogeneous soil into a uniform one (with unitary conductivity), in which the saturated flow is characterised by the same gradients when it takes place along corresponding paths. The obtained map $x^{*}\left(X^{*}\right)$ is related to the properties of the perched water tables, which can take place in the investigated soil. Particularly the slope at $X_{f}^{*}$ defines the threshold $i_{f}(\beta)$ and the thickness of any perched water table given by an infiltration rate $i(\beta)>i_{f}(\beta)$ is related to the chord starting in $\left(X_{f}^{*}, x_{f}^{*}\right)$ and with slope $i / \cos \beta$.
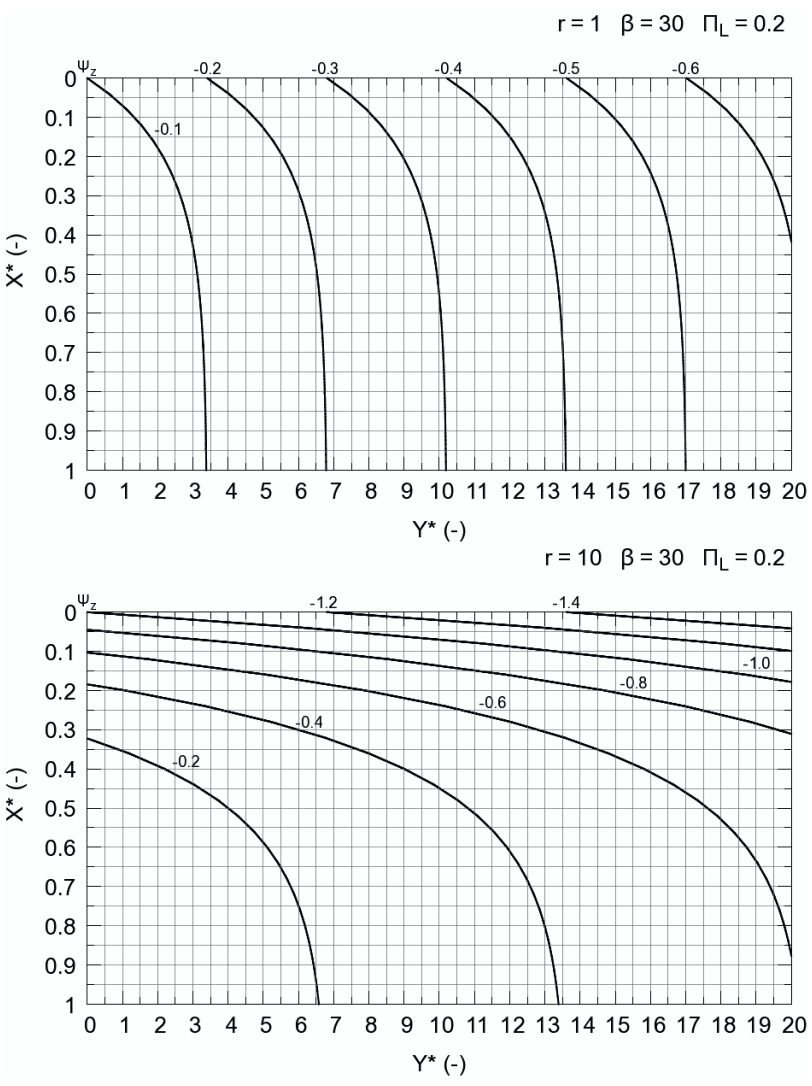

Figure 5. Lateral deflection of an infiltrated drop in a waterlogged sloping soil in presence of a perched water table. Only in these graphs $X^{*}$ and $Y^{*}$ refer to dimensionless variables, defined by $X^{*}=x^{*} / x_{f}^{*}$, and $Y^{*}=y^{*} / x_{f}^{*}[20]$.

As the soil conductivity profile is measured at certain depths and then interpolated on the basis of an analytical function $K_{s}\left(x^{*}\right)$, it is therefore of great importance the choice of the interpolating function, as different ones are characterised by different slopes and chords, thus affecting the prediction of the infiltration thresholds and of the properties of the perched water tables. 
As it was evidenced by Zaslavsky and Sinai in the third of their 1981's papers [21], during an infiltration process in a uniform or sharply-layered soil layer, of undefined length, laying on a sloping capillary barrier and eventually anisotropic (Figure 1), an infiltrated drop crosses the soil layer and it is laterally deflected by the slope and by the effect of the anisotropy. The same pattern takes place in a heterogeneous soil, as it is represented in Figure 5 by means of the Lagrange stream function $\Psi_{z^{*}}$ [20] which describes the flow field within a perched water table in a sloping soil at waterlogging, both in the case of isotropic (above, $r=1$ ) and anisotropic (below, $r$ $=10)$.

These results evidence that the soil layer is crossed by the drop in a finite lateral length (along the slope) and that, in a perched water table laying on a capillary barrier, the classical Dupuit-Forchheimer hypotheses for linear and gradually variable flow in the porous media do not apply, due to the meaningful transverse Darcian fluxes. On the other hand, as no hypotheses were introduced on the magnitude of the slope $\beta$, this framework to describe the flow within a perched water table is effective even in conditions of great slopes.

\section{Conclusions}

A theoretical framework to describe the relevant hydrological processes acting in a shallow, sloping and heterogeneous soil was presented (Section 2). The scheme evidences the important role played by the conductivity at saturation in the onset of perched water tables, which are among the most common shallow landslides triggering mechanisms. Some difficulties, some methodological aspects and some recommendations to measure the hydrological properties of soils in mountain environments were presented (Section 3). A focus was made on the importance of collecting information on the transverse heterogeneity of the hydraulic conductivity at soil saturation and on how to link the laboratory measured soil-water retention relationships with the field soil-water contents. Then the implications of the heterogeneity of the soil hydraulic conductivity at saturation on the properties of the perched water tables and on the characteristic infiltration thresholds were presented and discussed (Section 4).

\section{References}

[1] R. C. Graham. In: G. Certini, R. Scalenghe (eds), Soils: basic concepts and future challenges. pp. 151-163 (Cambridge University Press, 2006)

[2] M. Kirkby. In: R. Chorley (eds), Water, Earth and Man. pp. 215-227 (Taylor \& Francis, 1969)
[3] T. W. J. van Asch, L. P. H. Van Beek, T. A. Bogaard. In: L. Picarelli, P. Tommasi, G. Urciuoli, P. Versace (eds), Rainfall-induced landslides. Mechanisms monitoring techniques and nowcasting models for early warning systems. Proceedings of the $1^{\text {st }}$ Italian Workshop on Landslides. Vol. 1. Napoli (2009)

[4] T. A. Bogaard, R. Greco. WIREs Water. (2015) doi:10.1002/wat2.1126

[5] S. Barontini, R. Ranzi, B. Bacchi. Wat. Resour. Res. 43:W08411 (2007).

[6] S. Barontini, A. Clerici, R. Ranzi, B. Bacchi. In: Climate and Hydrology in Mountain Areas. pp. 101-121 (John Wiley \& Sons, Ltd, 2005)

[7] S. Barontini, A. Clerici, R. Ranzi, B. Bacchi. In: Hydrology in Mountain Regions: Observations, Processes and Dynamics. pp. 112-118. IAHS Publ. 326 , ISBN 978-1-901502-89-3 (2009)

[8] L. Wu, L. Pan, J. Mitchell, B. Sanden. Soil Sci. Soc. Am. J. 63: 788-792 (1999)

[9] W. D. Reynolds, D. E. Elrick. Soil Sci. Soc. Am. J. 55: 633-639 (1991)

[10] K. J. Beven, M. J. Kirkby. Hydrol. Sci. Bull. 24: 4369 (1979)

[11] Y. Mualem. Wat. Resour. Res 12: 513-522 (1976)

[12] T. Vogel, M. Cislerova. Transport in Porous Media 3:1-15 (1988)

[13] K. W. Watson, R. J. Luxmoore. Soil Sci. Soc. Am. J. 50:578-582 (1986)

[14] M. Peli, S. Barontini, T. A. Bogaard, B. Bacchi, R. Ranzi. In: C. Mancuso, C. Jommi and F. D'Onza (eds.), Unsaturated Soils: Research and Applications, Vol. 2. pp.167-174, (Springer, Heidelberg, 2012)

[15] S. Barontini, G. Belluardo, B. Bacchi, R. Ranzi. In: Atti del XXXI Convegno di Idraulica e Costruzioni Idrauliche, pp. 9 (Morlacchi, Perugia, 2008)

[16] S. Barontini, M. Falocchi, R. Ranzi. In: Lollino G., Giordan D., Crosta G.B., Corominas J., Azzam R., Wasowski J., Sciarra N. (Eds.) Engineering Geology for Society and Territory. Volume 2: Landslide Processes, pp: 2153-2156 (Springer International Publishing, 2015)

[17] S. Barontini, R. Ranzi. In: Atti del XXXII Convegno Nazionale di Idraulica e Costruzioni Idrauliche, 10 pp. (Walter Farina Editore, Palermo, 2010)

[18] S. Barontini, M. Peli, T.A. Bogaard, R. Ranzi. In: C. Margottini, P. Canuti, K Sassa (Eds.) Landslide Science and Practice Volume 3, pp: 143-149 (Springer Berlin Heidelberg, 2013)

[19] D. Zaslavsky. Soil Sci. 97: 400-410 (1964)

[20] S. Barontini, M. Peli, R. Ranzi. In: Proceedings of the Second IAHR European Division Congress, 6 pp. (2012)

[21] D. Zaslavsky, G. Sinai. J. Hydr. Div. ASCE 107: $37-$ $52(1981)$ 